\title{
Gender Representation And Identity Construction In Pakistani Print Advertisements Of Clothing Brands: A Socio- Semiotic Analysis
}

\author{
Mehreen Umar \\ \& \\ Sarwet Rasul \\ Department of English \\ Fatima Jinnah Women University
}

\begin{abstract}
The linguistic choices and graphical representations used in Pakistani print advertisements offer an interesting dimension in studying the ways in which gender identities are constructed. This study focuses on the nature of gender representation in Pakistan print advertisements of clothing brands and examines the general attributes given to men and women in Pakistani print advertisements. The purpose of the study is to explore the ways in which the print advertisements serve as a tool to construct, communicate and reinforce the long standing perceptions about gender identities. For this purpose a total of 102 advertisements are selected from a Pakistani weekly magazine Daily Times Sunday Magazine. Data is collected from 8 issues of this magazine published over a period of two months. All the advertisements of various clothing brands are taken to study how male and female identities are constructed and represented in the advertisements. A socio-semiotic approach to discourse analysis is used to study discourse, signs, symbols and other extra linguistic (semiotic) features used in the advertisements to construct and represent gender identities and to examine how the male and female models are portrayed in these advertisements with respect to style, posture, attitude, gaze, age, identity etc. The paper provides useful insights into the phenomena of gender representation and identity construction in the current Pakistani context.
\end{abstract}

Keywords: Gender Representation, Identity, Advertisement, Semiotic Analysis

$$
\begin{aligned}
& \text { ثلخص }
\end{aligned}
$$

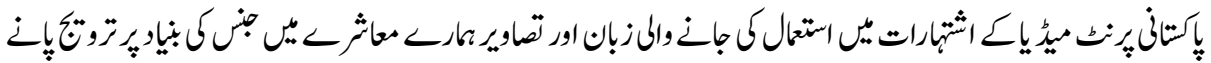

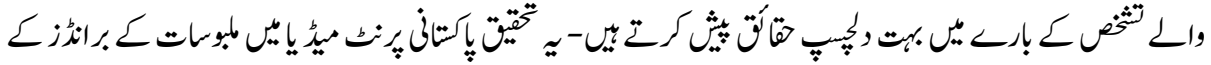

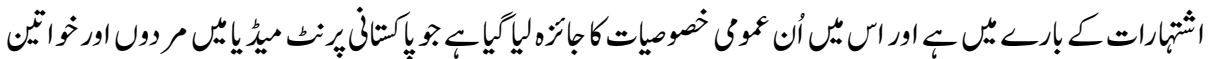

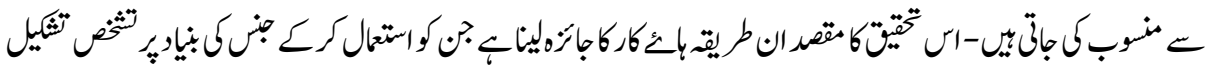

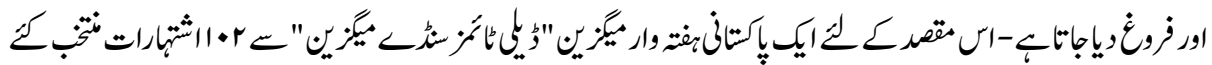

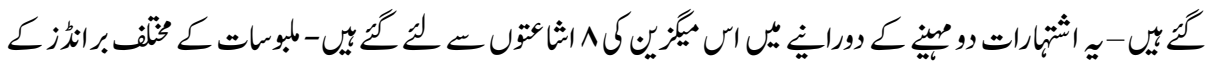




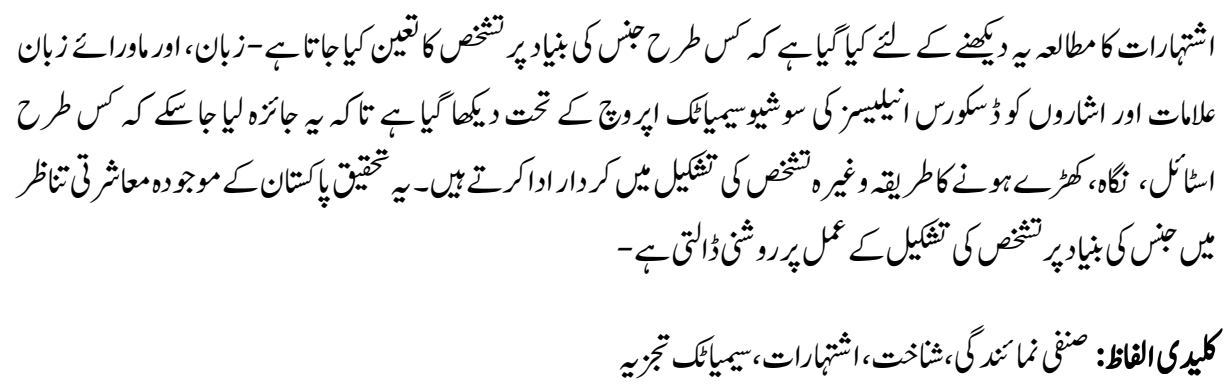

\section{Introduction}

The representation of men and women in advertisements has been the subject of study and discussion for over a long period of time as advertisements have a tendency to stereotype men and women in order to communicate the properties of the particular brands and to sell the products. As media has become increasingly influential in shaping the world's insight into the self, the struggle to maintain a unique identity and selfunderstanding away from the media influence becomes more and more difficult. As far as Pakistan is concerned, media has continued to reinforce gender stereotypes and hence there is an increase in gender stereotyping in our society. Advertising images that we see and experience over and over again have a very strong effect on our thoughts, emotions and behaviors. Advertising needs to be studied as a constituent part of our social reality, and not as a distorted reflection of it (Shields \& Heinecken, 2002).

The present study focuses on studying the gender representation in the print $\operatorname{ads}^{1}$ of various clothing brands in Pakistan. The study is conducted to examine the construction of gender identities in Pakistani print ads. The research also aims to examine the stereotypes found in these advertisements; the ways in which these stereotypes are constructed, broken, or reinforced; and also the ways in which new gender identities are being constructed.

\section{Gender and Print Media Advertisements}

Commercial advertisements have a tendency to stereotype men and women in order to ensure the sales of the product. The stereotyping not only reflects social reality but also creates certain versions of social realities. Print media advertisements continue to promote gender stereotypes by extensively depicting a woman serving the traditional roles such as housewives, mothers, baby-sitters and nurses. Men are continuously depicted as workers in offices, fathers, husbands and committed people to business. Men are also portrayed as involved in various other outdoor activities. Magazines and newspapers have continued to promote gender stereotypes through advertisements that send different signals to the masses that are negative as far as gender is concerned. 
Ads displaying men to be stronger and tougher, and women to be weak and fragile are another way of enforcing gender stereotypes. Social scientists suggest that although ads are generally made to promote specific items, they may have a lasting effect on people's beliefs, values, attitudes and even their behavior.

\section{Significance of the Research}

The present study explores the ways in which the Pakistani print ads serve as a tool to construct, communicate and reinforce the traditional perceptions about gender identities. The study is significant as it explores the gender representations in print media advertisements of clothing brands that provide the foundation for the construction and representation of stereotypes in the society.

The study of gender representation in the advertisements of clothing brands is particularly significant as recently there are numerous changes in the trends of advertising of brands in Pakistan. Various brands, especially clothing brands have emerged on the marketing scene of Pakistan. With the emergence of new media and with the effects of globalization, ways of perceptions of oneself, especially the clothing trends one follows, have changed in recent years. Now more than ever are people conscious of what they wear, and how they are perceived by others when following the trends of top clothing brands. The study focuses on the ways in which both men and women are portrayed in the advertisements of clothing brands of Pakistan to study how the gender identities are constructed through images in the Pakistani social context.

\section{Aims of the Research and Research Questions}

The aim of the research is to explore what types of gender images are presented in the print ads of Pakistani clothing brands; and how in the Pakistani social context these identities are created semiotically. In line with this aim the following research questions are designed:

Q.1 What dominant images regarding gender are prominent in the print advertisements of Pakistani clothing brands?

Q.2 What type of images of masculinity and femininity are present in these advertisements of Pakistani clothing brands through attire?

Q.3 How are gender identities constructed through gaze, gesture, posture and looks of the male and female models in Pakistani advertisements of clothing brands?

\section{Literature Review}

This section provides a brief review of the literature that is relevant to the current research. 


\section{Advertisements and Discourse Analysis}

Cook (2001) argues that advertising is a discourse itself constituting the meaning of both the text of the ad itself and the context in which people respond to the ad. He argues that it is important to examine the meanings of ads based on how audiences construct these meanings based on their semiotic knowledge of images/signs, genre knowledge, needs, desires. Advertisers market their products in ways to grab the audience's attention. They provide appeals and claims that entice them to buy what they are selling. The consumers on the other hand buy the well-advertised and popular items.

Words and ideas with positive connotations are used to suggest the association of the positive qualities with the product.Discourse is no longer a study for its own sake. Discourse is viewed as a social practice (Fairclough, 1992). Foucauldian approaches consider discourses as systems of power/knowledge which are socially and culturally located and which construct subjects and their worlds (Gubrium \& Holstein, 2000).Discourse analysis helps the researcher to understand how and why language is used to construct an individual's identity in relation to the world.

\section{Sex and Gender}

Sex is a biological construction whereas gender is a sociological construction. Biology may determine our sex as male or female but culture shapes the content and conduct of what it takes to be a woman or a man (Fleras, 2001, p.112). Gender also refers to the culturally and socially constructeddifferences between females and malesfound in the meanings, beliefs, and practices associatedwith 'femininity' and 'masculinity (Lorber, 1994, p. 6). Thus, gender is more sociological in its orientation relating to 'masculinity' and 'femininity'. Gender identities 'are invented categories. They are the product of the cultural meanings attached to certain attributes, capacities, dispositions and forms of conduct at given historical moments' (Nixon, 1997, p. 301). Also, gender is a cultural construct that the media actively works to promote.

\section{Gender Representation in the Media}

Study of gender representation is necessary for an analysis of power relations. It interplays with the construct of attributed and chosen identities.For most people, the identification and representation of oneself as female or male is the foundation of selfidentity. Media exposure shapes our attitudes about the proper roles and conduct of men and women. Worell (2002) believes that media focuses on the attitudes about the appropriate roles and behaviors of husbands and wives, the appropriateness of women's place in the domestic and work arenas, and the competencies and skills of each sex. It is due to the social context of gender that men may naturally be seen as more aggressive, 
overbearing, competitive and hierarchically oriented; and women, on the other hand, may naturally be seen as more submissive, encouraging and nurturing, passive, and domestically oriented.

\section{Impacts of Gender Stereotyping}

Advertising is much more persuasive than informative. Johnson and Ensslin also noted the power of discourse in transferring ideologies:

We are engaged in an almost constant process of encoding and decoding linguistic and non- linguistic messages. Consequently, we are subjected to, as well as in control of, plethora of technological and medical information flows that both construct and transfer ideologies between ourselves, our information providers, and our target audiences. (2007, p. 11)

Indeed it can be argued that advertising has, over time, become less concerned with the communication of information about commodities and more concerned with the manipulation of social values and attitudes in a way that persuades us into patterns of consumption and consumerism (Woods, 2006).

\section{The World of Advertisements and Branding in Pakistan}

Advertisements are designed in an attempt to assist the producers appeal to the customers or audience and attract their attention to the advertised brands and its various features. According to Jackson (2003) brands are 'a mixture of tangible and intangible attributes, symbolized in a trade mark, which if properly managed, creates influence and generates value' (p. 59). Brands can be products, services, or people, and advertising is about promoting the brands for the producers into the consciousness of buyers (O' Guinn et al., 2003).Advertising has established itself as the most important selling media in the modern age (Khalid, 1990). As with the electronic media, print media such as newspapers and magazines also display a gender bias in the portrayal of women and men in the advertising texts, i.e. in the language used, pictures, and other semiotic signs and symbols (Furnham \& Bitar, 1993).

The business industry in Pakistan relies heavily on the advertising industry to promote their respective brands. In Pakistan advertisements on the various modes of media such as television, newspapers/ magazines, virtual media etc. are used by the commercial fraternity to promote their brands. In Pakistan the traditional media, such as print media and television, are the most common modes of media. In recent years various channels of media have become free to use language and images to promote the identity of their products. A variety of images, pictures, and models are being used in advertisements, especially in the print advertisements, to attract the audience, and to promote and sell not only the products being advertised but also the underlying thought patterns that are not only the products of existing socio-cultural contexts but also the creators of new social realities. 


\section{Gender Identity Constructions in the Pakistani Media/Advertising Contexts}

The exploration of gender representation in the print advertisements means examining the way in which media represents both men and women. Such a study is important as certain stereotypes about men and women are constantly reinforced in the media. Women in particular have been portrayed either as housewives who are dependent on men, or as attractive objects in advertising (Craig, 1992).Similarly, the women in the Pakistani media contexts are continuously being portrayed in certain stereotypical ways. In the ads of edibles and home appliances women are generally portrayed in nurturing roles such as housewives and mothers; whereas in the ads of clothing and accessories, they are portrayed as sensual objects deemed significant for selling of the product. Most of the clothing ads establish women as sex objects, obsessed with the ideals of beauty and physical appearance. Men, on the other hand, are portrayed as strong, confident, and selfassured in Pakistani advertisements.

The images presented in advertisements are not only reflective of social realities, but also very subtly construct these realities. The advertisements usually contain very elusive clues about gender roles in the society and may function as socializing mediators in reinforcing these clues on societal levels. Signorielli (1989) has asserted that the genderstereotyped attitudes are affected by the exposure to gender role stereotypes in advertisements among the members of the society. Similarly, the female stereotypes in advertisements have an effect on the role of women in society in general and also on the cultural ideas of beauty. Kilbourne (1999) believes that when women are portrayed in advertisement only as an object of beauty by emphasizing certain parts of their body, this fake image of women in the media encourages other women in society to buy certain beauty products. Likewise, in the clothing advertisements in Pakistani media contexts, young women are shown to be having beautiful skin and hair, thin bodies, and perfect faces. As a result the modern Pakistani woman is pressured to have a perfect personality, mainly dependent upon physical beauty.

\section{Data Collection}

Data for the current research is collected from a Pakistani weekly English magazine called Daily Times Sunday Magazine. A total of eight issues of the magazine from two months i.e. $3^{\text {rd }}$ August, 2014 to $4^{\text {th }}$ October, 2014 are selected for analysis. The data comprises of all the ads of Pakistani clothing brands for adults. The ads having no gender representation, i.e. ads without models have not been included in the data. These brands are considered to be some of the most famous brands in Pakistan. The ads are selected to study how male and female (gender) identities are constructed and represented in the ads by various semiotic elements present in the text of the ads. 


\section{Presentation of Data}

The complete data is presented in the Appendix. However, the ads which are repeated in the data have been presented in the Appendix only once to avoid repetition. On the other hand, to support the qualitative claims made in the analysis, the representative sample of ads is included in the analysis as well.

The quantitative aspects of the data such as the number of advertisements in the selected issues of the magazine, number of male and female models, number of advertisements featuring male and female models, etc. are presented in Table 1:

Table: 1

Quantitative aspects of the Data

\begin{tabular}{|l|c|c|c|c|}
\hline Aspects & No. of ads & Male models & $\begin{array}{c}\text { Females } \\
\text { models }\end{array}$ & $\begin{array}{c}\text { Both male and } \\
\text { female models }\end{array}$ \\
\hline Ads/ brands for men & 23 & 38 & -- & -- \\
\hline Ads for women & 57 & -- & 77 & -- \\
\hline $\begin{array}{l}\text { Ads for both men and } \\
\text { women }\end{array}$ & 22 & 7 & 10 & 7 \\
\hline Total & $\mathbf{1 0 2}$ & $\mathbf{4 5}$ & $\mathbf{8 7}$ & $\mathbf{0 7}$ \\
\hline
\end{tabular}

Table 1 shows that 87 female models and 45 male models feature in a total of 102 ads, whereas, in 7 ads both male and female models are used. A total of 79 ads feature women, whereas a total of 45 ads feature men. This shows that female models are used in maximum number as compared to the male models. Also, the ads designed specifically for women clothing brands are also in greater number than the ads explicitly designed for men's clothing brands which refers to the social reality where in the Pakistani context clothing brands for women are in a far greater number than the clothing brands for men.

\section{Analytical Framework}

The approach used to analyze gender representation in the ads is socio-semiotic approach to discourse analysis. This approach provides with a method of analysis that focuses on the analysis of semiotic features, likewise studying the usage of these features, and linking the sociological aspects involved in the practice. The current analysis, thus, focuses on the gender representation in print advertisements of clothing brands.

Socio-semiotics is concerned with the analysis of semiotic resources. The term semiotic resource is used to describe the resources such as language, image, music, gesture and architecture. Language is the most important and dominant sign system for humans, but there are numerous other sign systems. All systems can be analyzed using semiology (O’Shaughnessy \& Stadler, 2002). Following Halliday (1978, p. 123), semiotic resources are 'system[s] of meanings that constitute the 'reality' of the culture'. Since the current 
research focuses only on the print ads as data, semiotic resources in the data would include gestures, gaze, attitude, style, pose, etc. of the models in the ads.

\section{Findings and Analysis}

The data is analyzed with reference to specific features present in the ads such as gaze, posture, style and attitude, age, roles played, eastern and western identities, and bridal feminine and masculine identities. The qualitative findings focusing on the qualitative aspects of the analysis are presented as under.

\section{Female Portrayal}

A total number of 87 female models are featured in a total of 102 advertisements out of which 77 female models are shown in 57 ads that are specifically meant for women. It is interesting to note that the female models are given different looks in the ads depending upon the kind of wear they are endorsing. The advertised clothing found in the data can be divided into Eastern wear, Western wear, and bridal couture. The analysis of the female portrayal includes the study of certain features in relation to the female models in the ads such as gaze, posture, style and attitude, age, roles played, and eastern, western and bridal feminine identity. All these aspects are discussed here:

\section{i. Gaze}

To accentuate the eastern look in the ads of eastern wear, the women are shown with modest looks, eyes directed away from the camera, rather having a lowered gaze to such an extent that the eyes almost look closed. Consider Fig. 1 and Fig. 2.

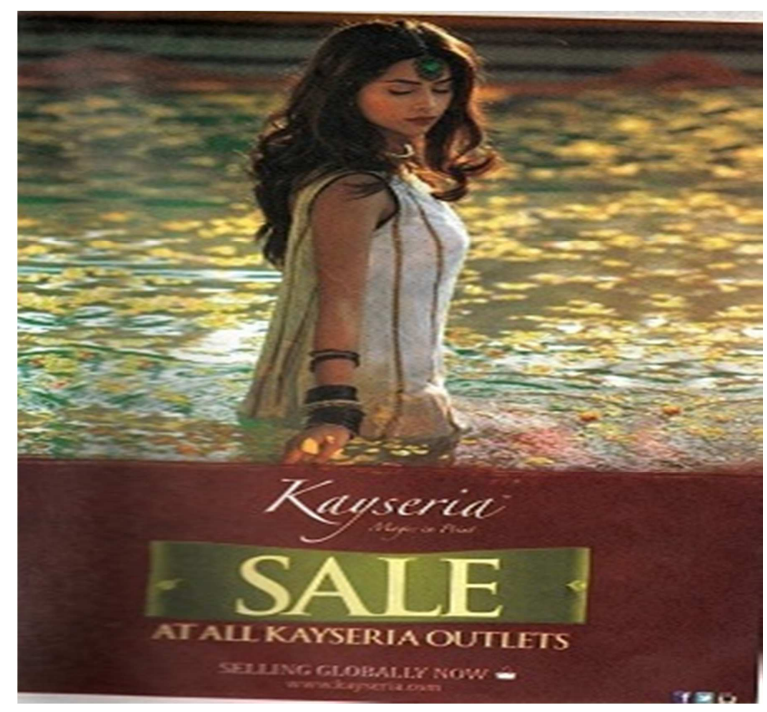

Fig. 1

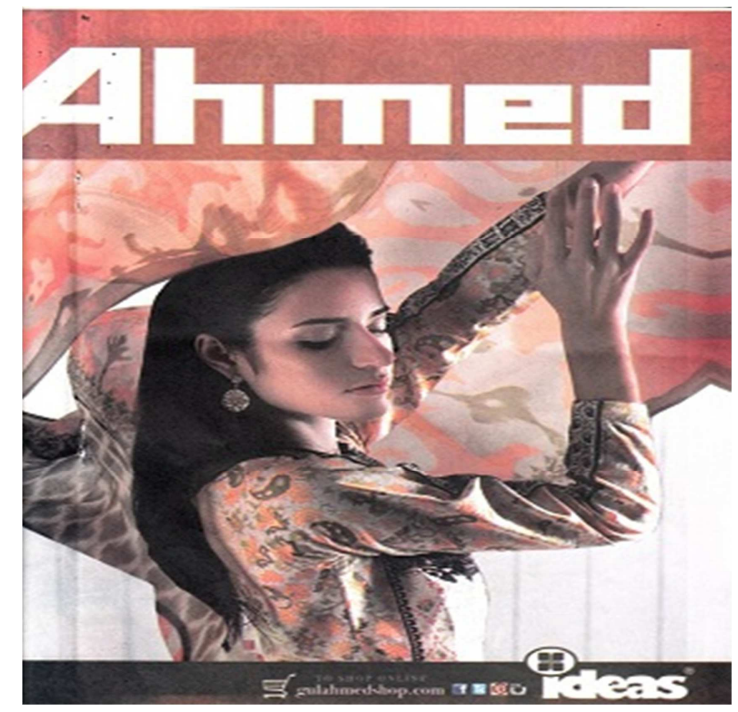

Fig. 2 
The most common feature of these ads is the lowered gaze of the female models or their gaze away from the camera. The lowered gaze takes away any agency from these women in the ads and gives them all the more a very shy and timid look. Even when the gaze is not lowered, it is presented in such a way that it gives the woman model the same lack of agency or confidence as is the case in the lowered gazes. See Fig. 3 and Fig. 4for example.

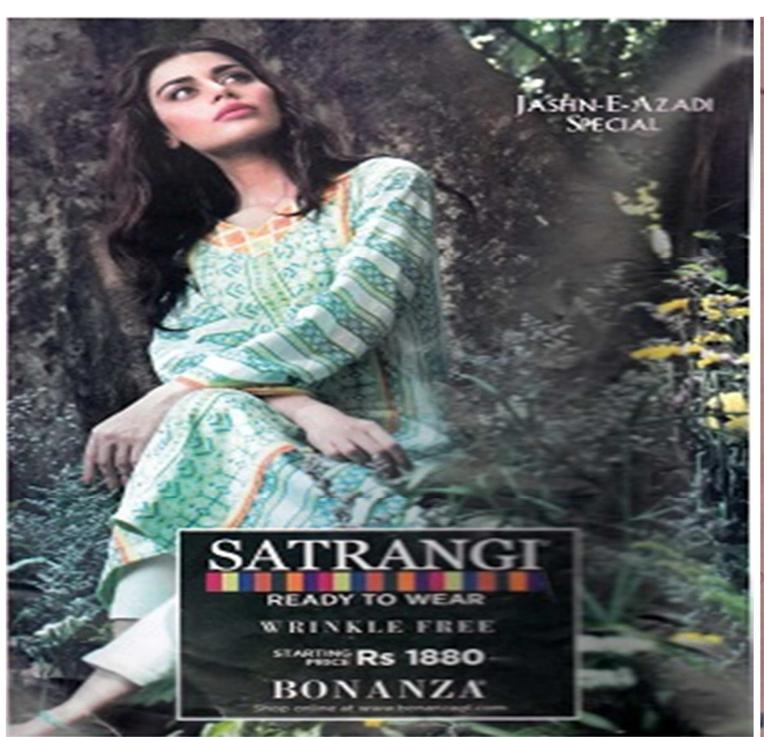

Fig. 3

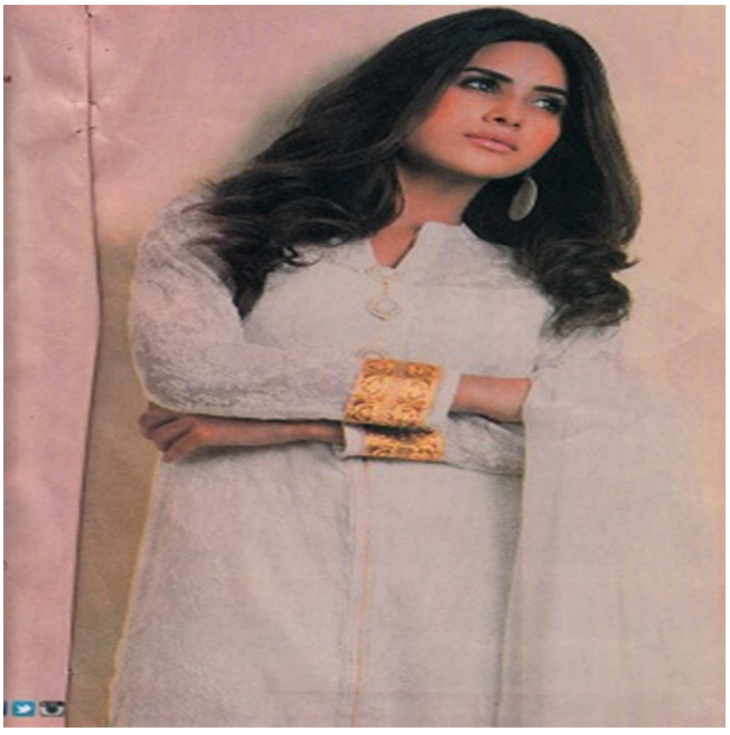

Fig. 4

In Fig. 3 and Fig. 4, though the gaze is not lowered as in Fig. 1 and Fig. 2, the upper gaze still does not seem to be a characteristic of confidence or self-assurance; rather the eyes are dreamy, giving the women the same coy and timid look.

The direct gaze is representative of boldness and confidence which is usually not associated with a typical eastern Pakistani woman. Hence, the direct and confidant gaze is witnessed in only those ads where the woman model is shown to be bold, confident, and having a modern western identity. Consider an ad by 'Chinyere' for women (Fig. 5). 


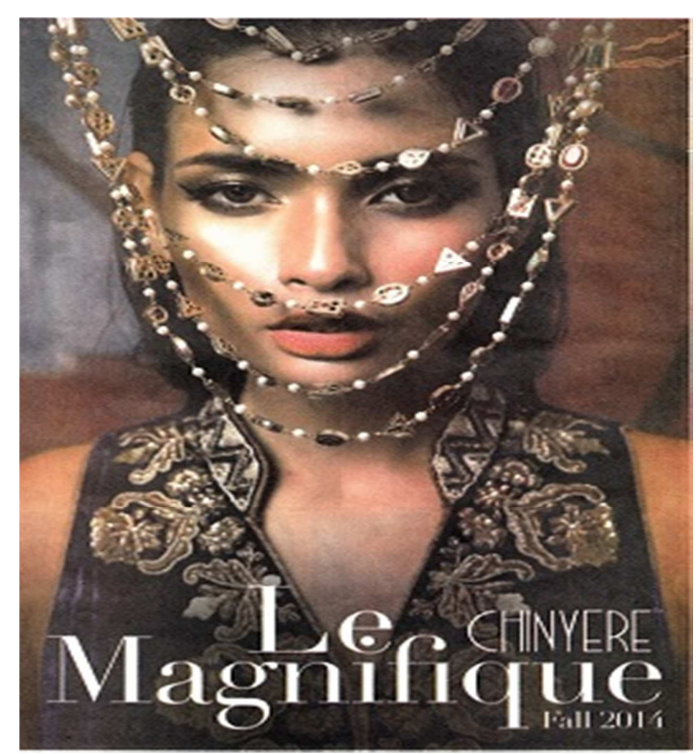

Fig. 5

In Fig. 5, only the face of the model is shown who is looking directly at the camera, with tied up hair and parted lips, giving a sensuous look. The clothes that she is supposed to model or endorse in the ad are almost invisible from the viewers' sight as the focus is more on the face and specifically on the eyes. What is most remarkable here is that as contrasted to the male models, who are shown in sunglasses in a couple of ads, in none of the ads a woman is shown to be wearing sun-/glasses. In case of female models eyes are used in advertisements to create a sensual look and there is a big focus on the facial features of the female models, the eyes or any other facial features are seldom hidden behind any cover. Rather the face is highlighted using make-up, jewelry, or even sometimes with sensuous expressions.

\section{Posture, Style and Attitude}

There is a greater emphasis on female face, body and expressions. Even if the face is not shown some part of the body is shown in the ad to sell the product. For example in an ad of a western wear for women (Fig. 6) the faces of the female models are not shown but only their bodies clad in the specific clothing of the brand from the chin down to the knees of the models are shown. 


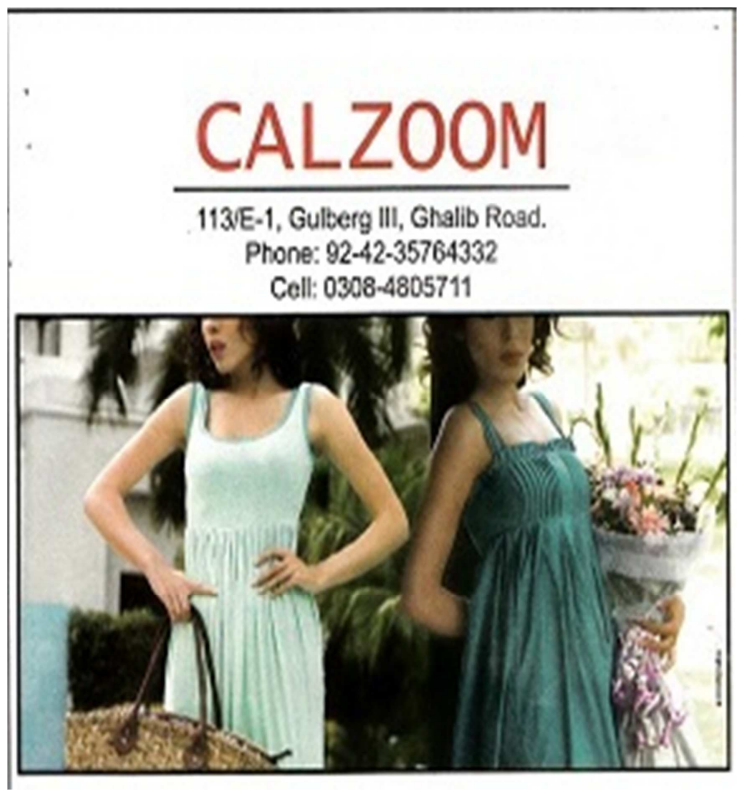

Fig. 6

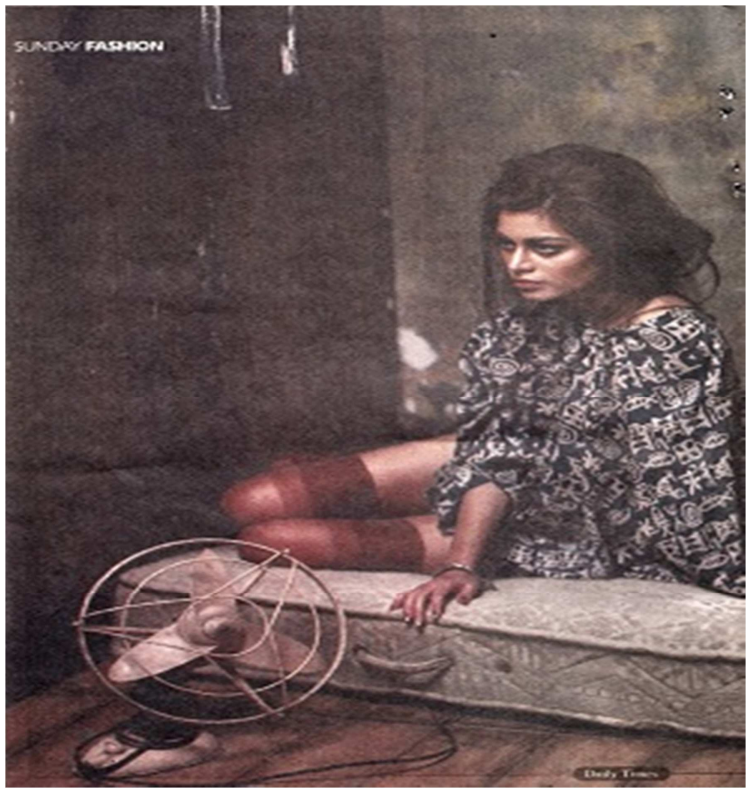

Fig. 7

Similarly in another ad of western wear (See Fig. 7) a woman is shown sitting on a bed exposing her bare legs. Thus the depiction of sensual images of women seems a very common practice in today's Pakistani advertising. This also type of representation also reinforces the stereotypical corporal role assigned to women in the media in general.

\section{Age Factor}

According to Goffman (1979) the depiction of women in advertisements is quite different from the real women we see every day in our real lives and that such portrayals in advertisements prove to be lethal for the common women's self-esteem. It is observed that all the women in the selected ads are skinny, young and beautiful, as evident in Fig. 8 and Fig. 9: 
Brands: A Socio-semiotic Analysis

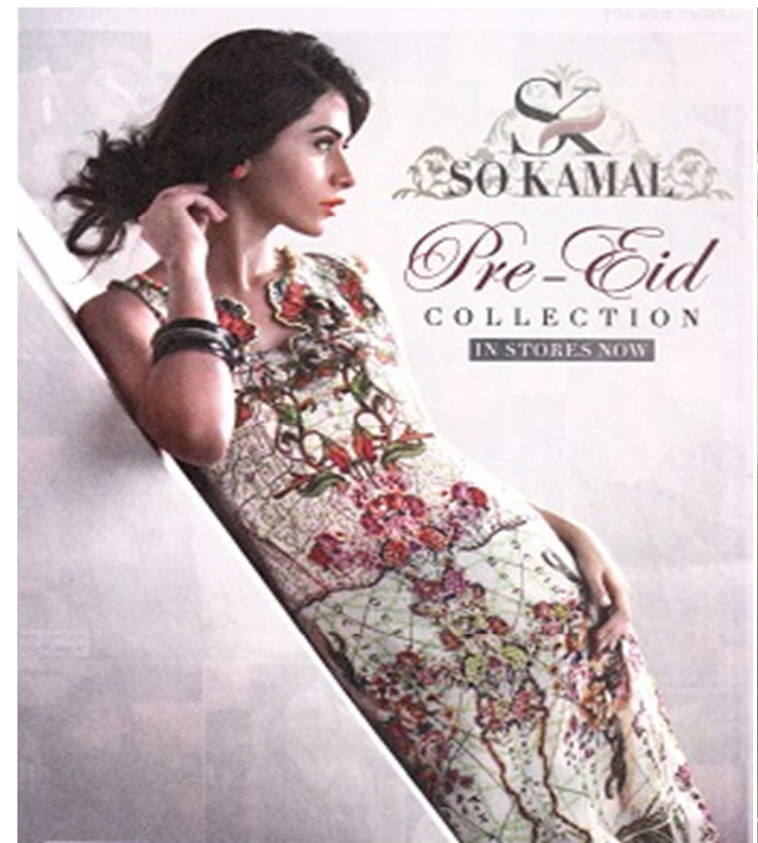

Fig. 8

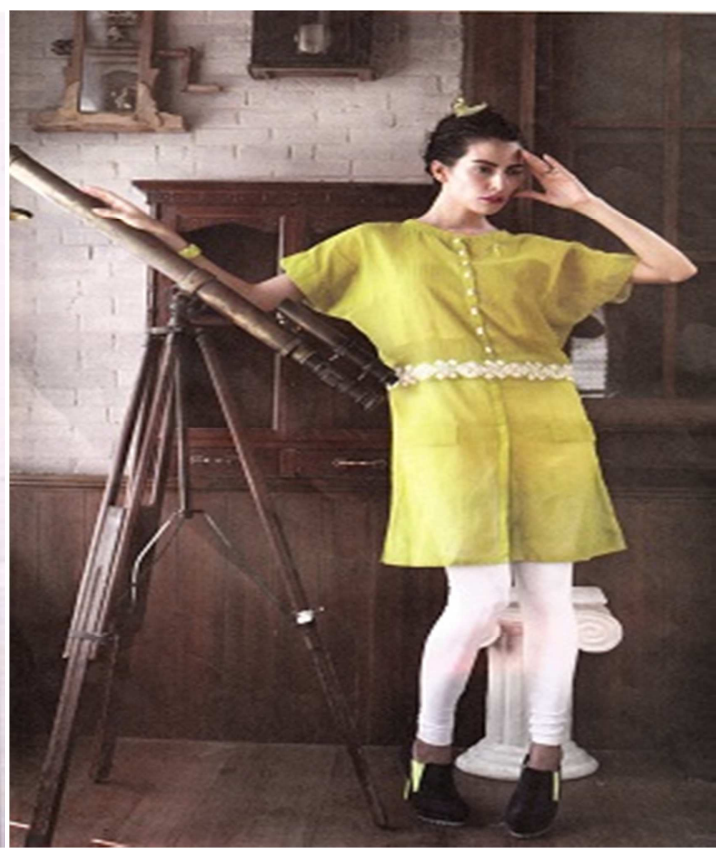

Fig. 9

All the ads in the data fail to represent the real variety of women's ages, shapes, sizes and colours. In a total of 79 ads that feature 87 women, none of the ads has an older woman being presented as a model. All the female models used in the ads in the data are pretty, young, and skinny (See Appendix 1).Women of all ages get the message that they must be flawlessly beautiful, young, and above all, they must be thin. This shows that the longstanding practice of portraying young and beautiful women in ads to sell products is still prevalent in today's Pakistani advertising world.

\section{Roles played/ Activities performed}

In almost none of the ads in the data is seen a woman who is shown to be performing some productive activity. All the female models in the ads are just shown posing for the camera (See Fig. 10 and Fig. 11 in this regard). 


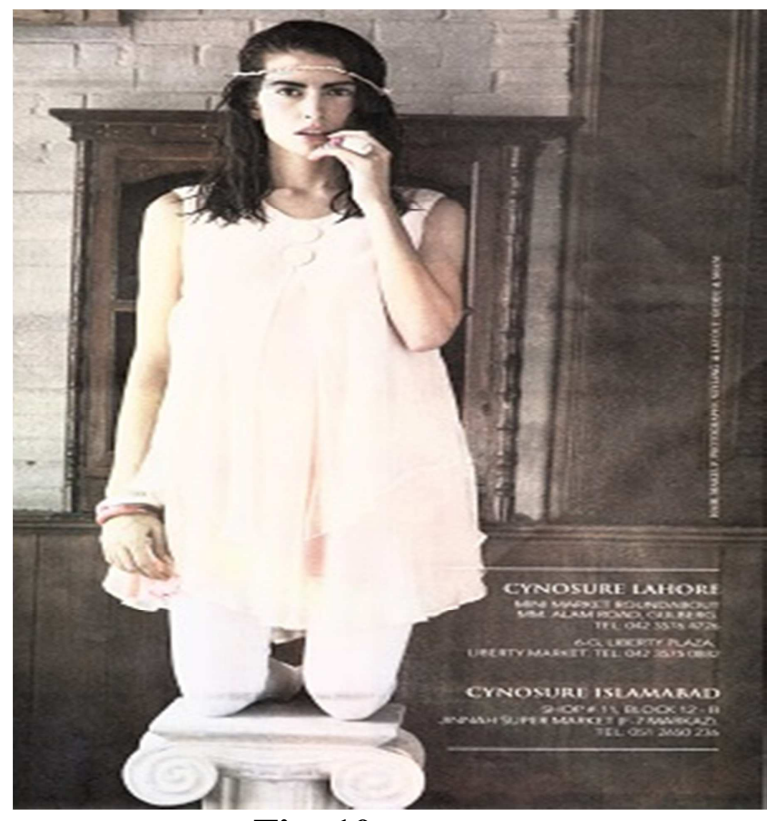

Fig. 10

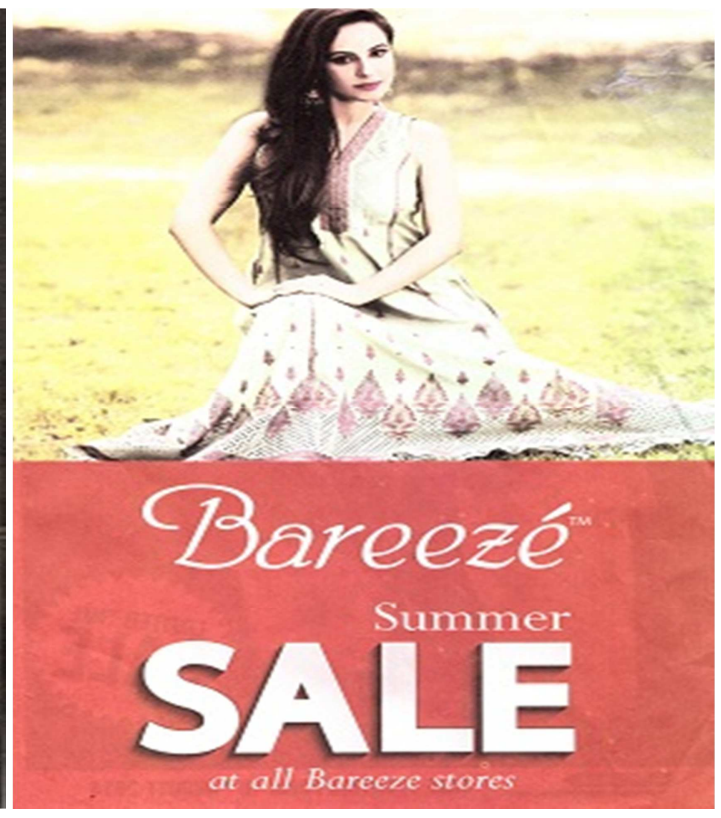

Fig. 11

Not only in these illustrations, but in almost every ad women are portrayed as merely models who are modeling for the camera, and not shown to be involved in any kind of significant activity. The images in all the ads indicate that no particular role is assigned to them other than being a model for endorsing the product. Even in the outdoor photo shoots the women are seen to be only posing for the camera.

\section{Identity}

In the data female models are shown modeling eastern and western wears both. The findings indicate that the women in the ads for eastern feminine wear have certain common characteristics. These characteristics or 'semiotic resources' such as postures, dressing, gaze, attitude, etc. represent the eastern feminine identity. Fig. 1, 2, 4 and 11 that are already shown with reference to other categories can be considered as examples of semiotic resources for the eastern feminine identity.

In the ads for western wear one of the most common features present is sensuality. The women in the ads are seen exposing some parts of their bodies to give a corporeal feel. Consider Fig. 12 for instance. 


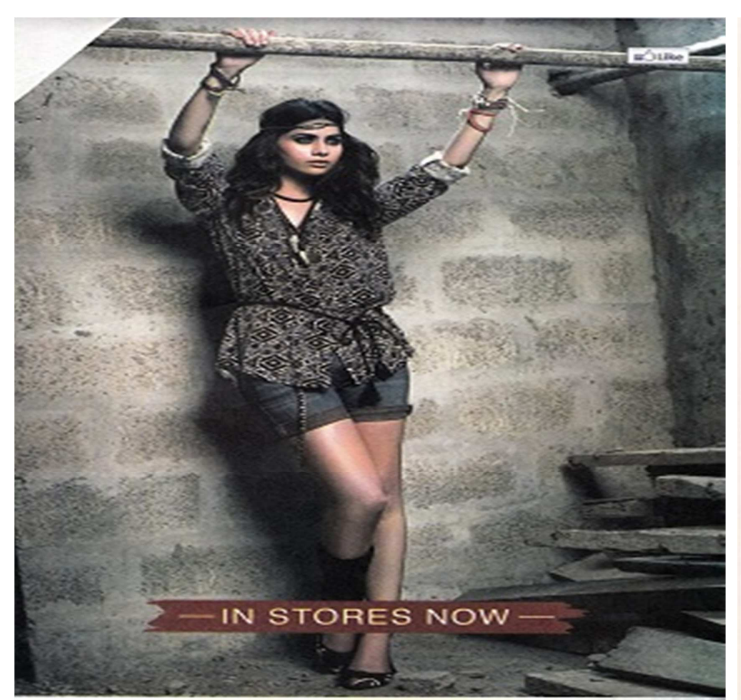

Fig. 12 (a)

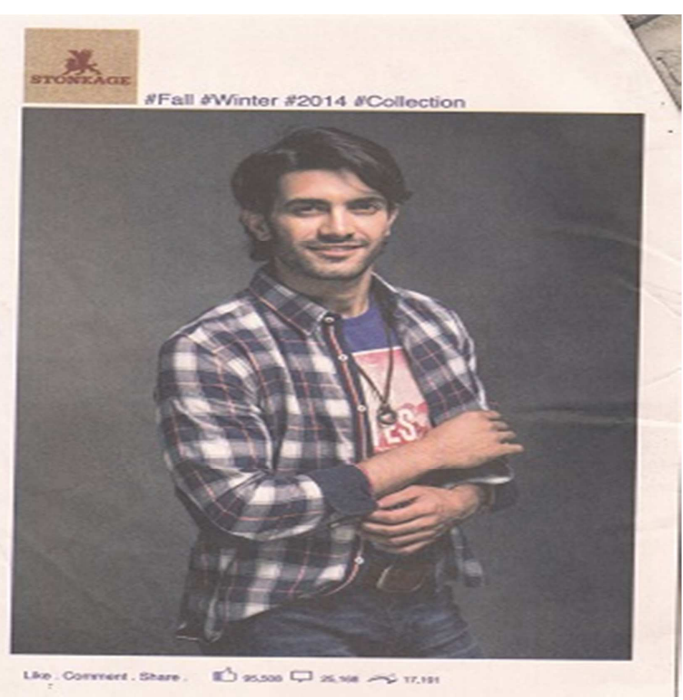

Fig. 12 (b)

In Fig. 12 (a), a woman is seen wearing shorts, holding on to a pole with her hands raised above her head. The smoky eye makeup and parted lips give a somewhat sensual overtone to the whole image. What is worth noting here is that in the same ad a male model is also shown [Fig. 12 (b)] but his image is of a stylish and cheerful person who is smiling at the camera. Only the upper half of his body i.e. body down to the waist only is shown, unlike the female model whose full body clad in western wear is shown. This emphasizes the focus of advertisements on the maximum exposure of a female body as compared to men.

Similarly, in Fig. 13(a) and Fig. 13 (b) the focus is on the sensual feel in the ad:

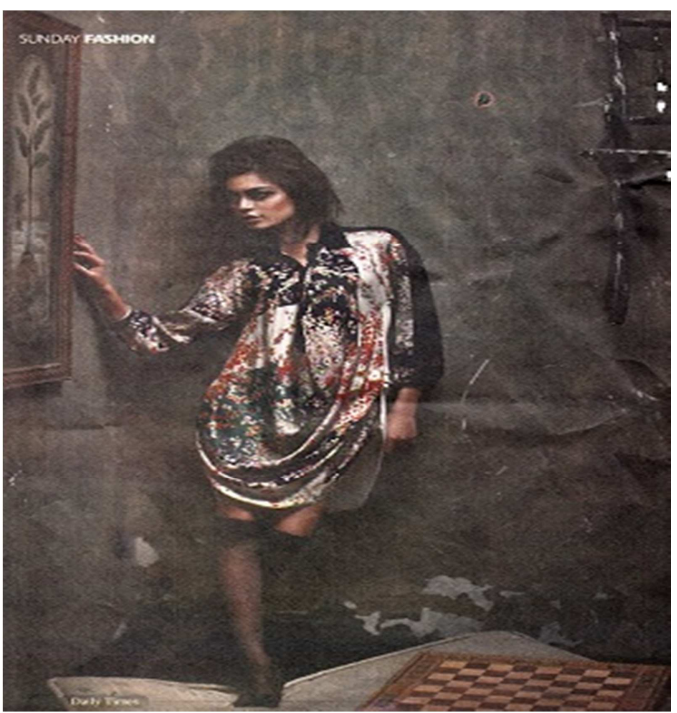

Fig. 13 (a)

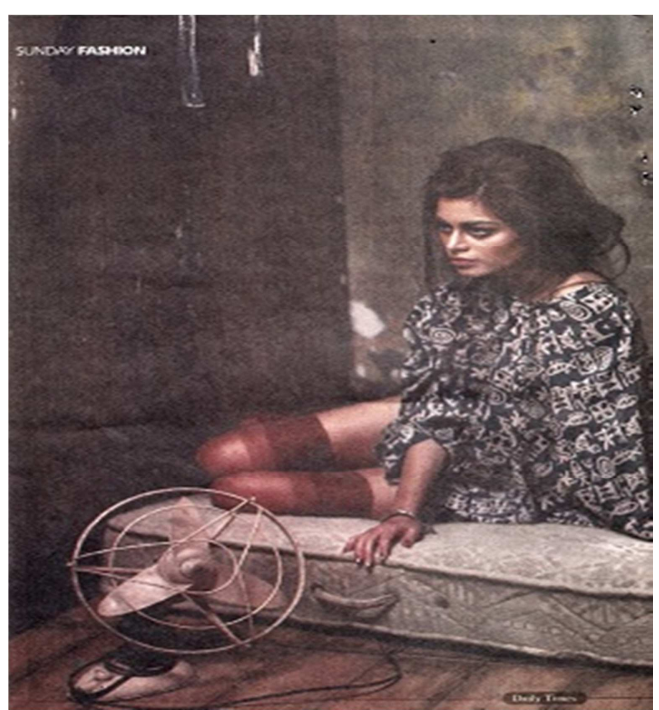

Fig.13 (b) 
The woman in both the pictures is shown with knee length stockings and uncovered thighs in both the pictures of the ad. In one of the images she is seen as sitting on a bed and in another she is seen leaning against a wall. Hence, it can be concluded that sensuality is one element that is associated with the modernized western identity in the media, especially in the print media. Another feature associated with the western identity is independence, style, and experiment. In Pakistani context the modern women who dress up in a western style are usually considered to be confident and outspoken, as in Fig. 14 (b), the caption 'Coco girl is fashionable, confident and a guaranteed head turner!' indicates the new untraditional and modern western identity of the modern Pakistani woman.

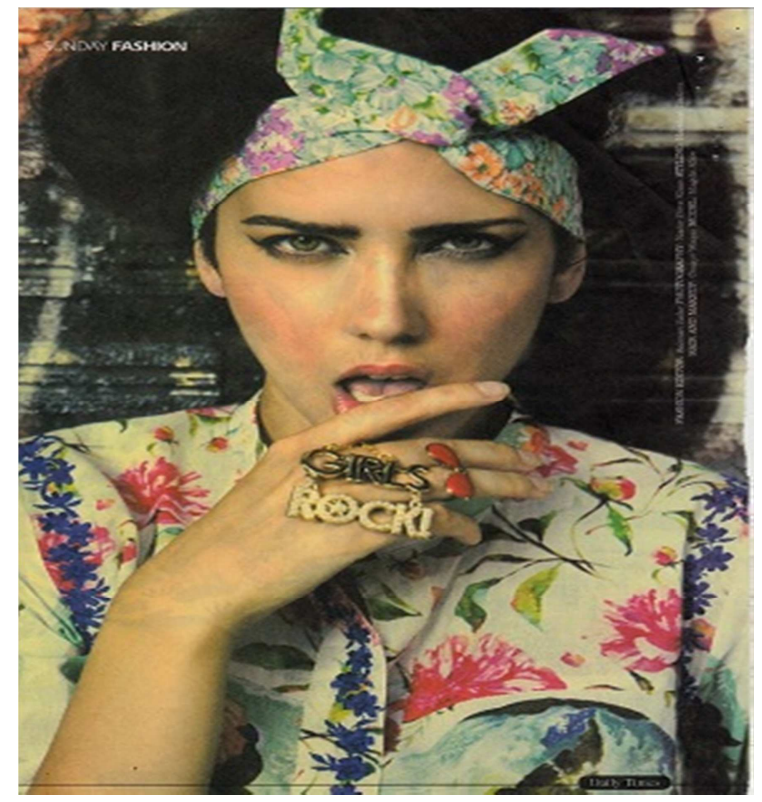

Fig. 14 (a)

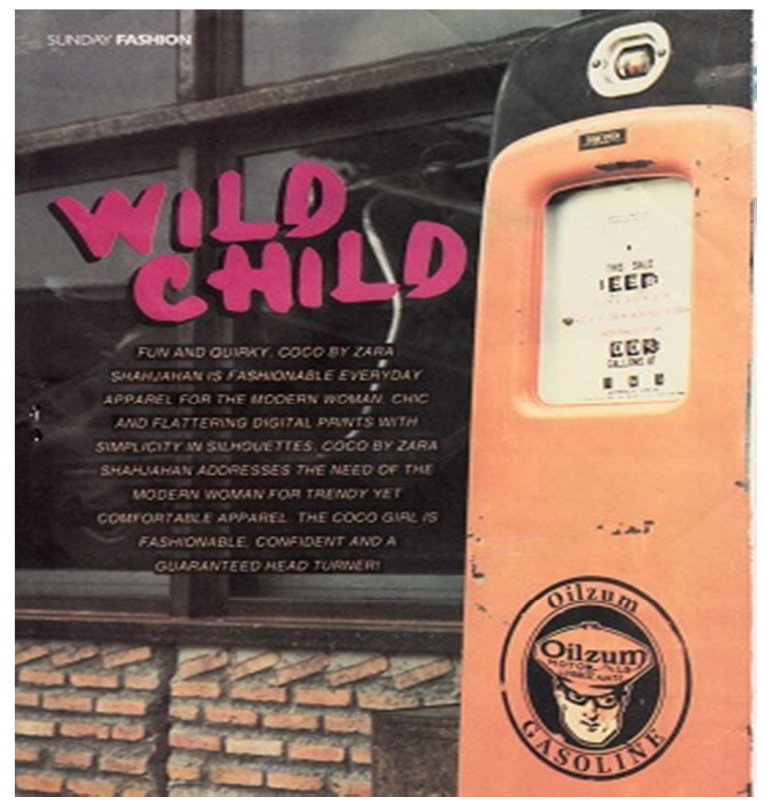

Fig. 14 (b)

The image in the ad shows a girl in a floral print shirt. She has wrapped a locket around her hand that has 'GIRLS ROCK' written over it. The hand is put over her mouth which is open with a glimpse of teeth and tongue, thus adding an element of sensuality to the picture. Even the name of the collection i.e. 'Wild Child' [see Fig. 14 (b)] indicates the unconformity to the longstanding and traditional feminine identity associated with east. Hence, the findings indicate that the western feminine identity is associated with sensuality, modernity, freshness, and flirtatiousness, unlike the eastern feminine identity which is associated with traditionalism, shyness, dependence, lack of confidence etc.

Furthermore, contrary to the domestic and submissive role assigned to women in the print ads, there is now a new kind of identity ascribed to women in some ads. Though the domestically oriented housewives still rule the stage of ads of edibles and home appliances, this new kind 
of identity is attributed to give women somewhat more sensual appeal. Women are now depicted as having flirtatious natures by giving the sensuous looks with their eyes and parted lips. This practice is more common in the ads of Western wear where the focus is more on showing the women as having modern Western identities contrary to the shy and timid image of the traditional Eastern women. Consider Fig. 17 in this regard.

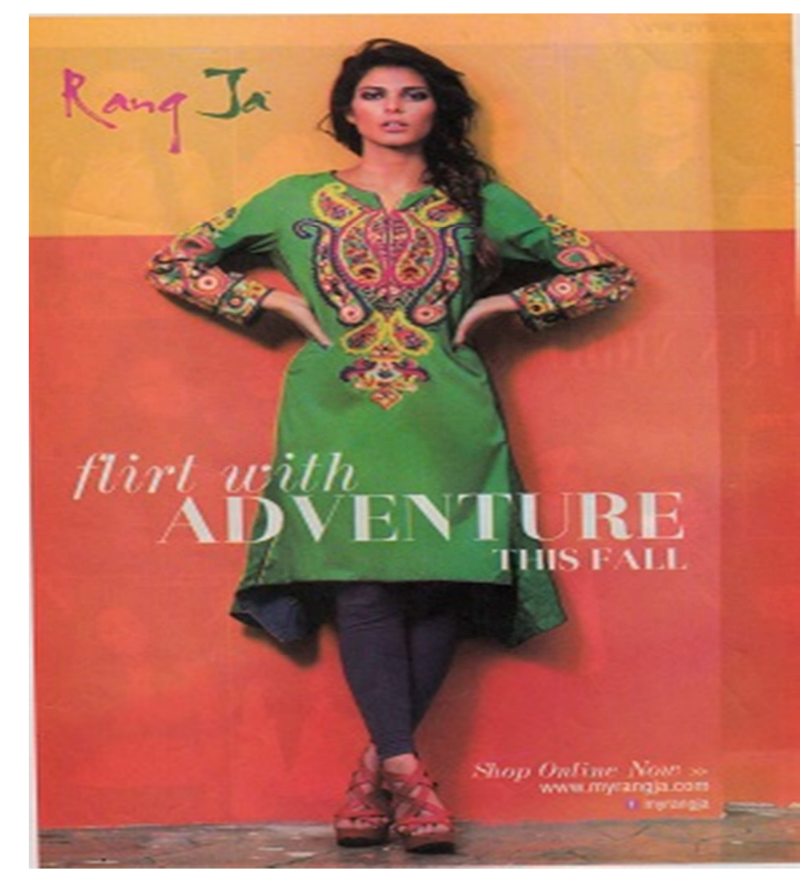

Fig. 17

Here a girl in a comparatively short shirt, tight pants, long heels, hair let loose on one side, parted lips, hands on waist with a direct gaze at camera, along with the caption 'flirt with ADVENTURE THIS FALL', suggests the modern western identity of today's young Pakistani woman who is adventurous and ready to experiment with the new fashion. This image is reflective of the working women in the Pakistani context who now have more exposure to the world outside the realm of their houses.

\section{Bridal Feminine Identity}

In all the ads of the brands for bridal wear, there are images of women all decked up as brides wearing all the possible ornaments associated with femininity in the east. Consider for instance Fig. 15 and Fig. 16, where the women are shown wearing heavy jewelry, bridal gowns, with a timid and shy look on their faces. 


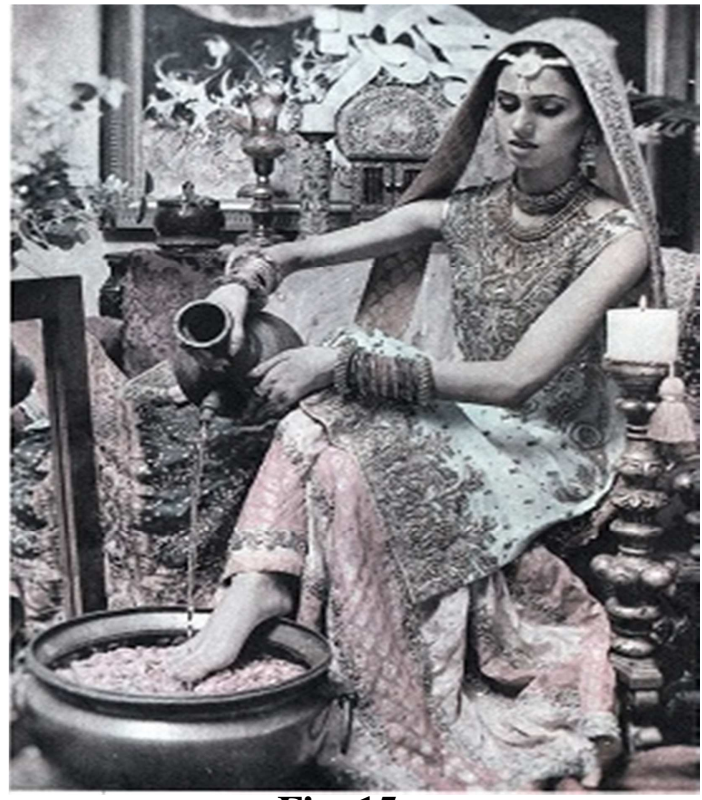

Fig. 15

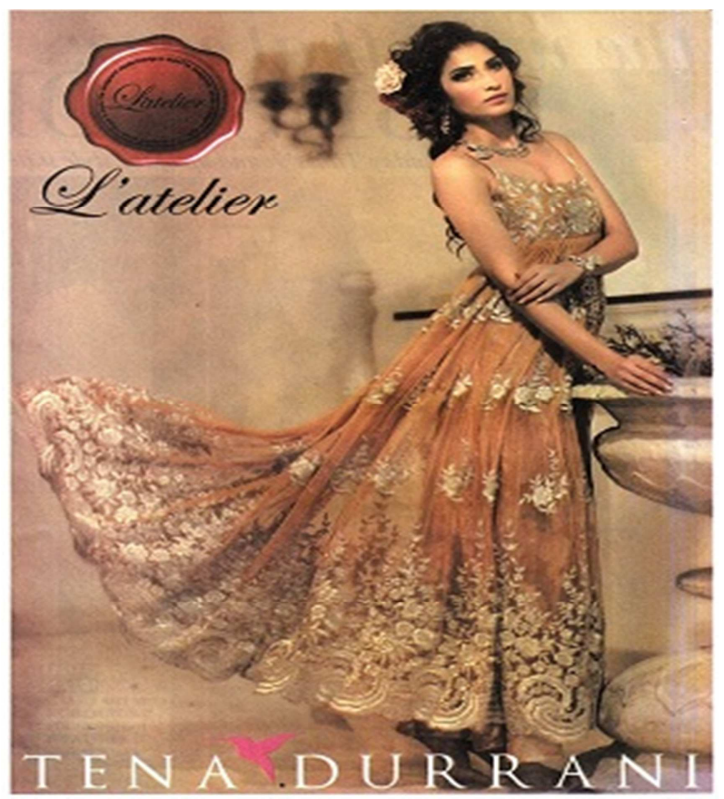

Fig. 16

In Fig. 15, the bride is sitting with her head covered with a duppatta, wearing a sleeveless gown, jewelry, parted, lips, gazing downward pouring water on her feet put on a pot filled with water and petals. The very idea of the whole image gives the bride a shy look very typical of an eastern feminine bride. Traditional furniture is also seen in the background that adds to the traditionalist implications attached to the whole idea of marriage. The whole image corresponds to the traditional identity of a Pakistani bride which is associated with qualities like shyness, diffidence, and reserve. Hence, not only are the shy facial expressions giving a coy and timorous air to the brides, but also their very statures, ways of sitting or standing, the lowered gaze etc. all give add to the typical look of a Pakistani bride.

Similarly, in Fig. 16, the bride is shown in a long bridal gown with flower sequences on it, necklace, bracelet, earrings, flower garlanded in her hair, and loosely made hair. What contributes to the shy image of the bride is her gaze which is directed elsewhere with dreamy eyes, also her attitude and pose in which she is seen holding one arm with her hand, leaning bare foot on a big flower pot. To relate the same traditional eastern identity with the clothing lines been advertised, all the women in the ads of bridal couture are typically dressed up in traditional Pakistani wedding attires, and the poses, style and gaze of the models also insinuate the traditionalism of a Pakistani bride. However, a closer look at both the figures shows that the traditional eastern identity is being redefined. For example in Fig. 16, right from the way the bride is supposed to sit or stand, to the kind of attire she is wearing there are hints of deviations from the traditional eastern identity. The attire is eastern but more trendy and with a western outlook as apparent in the deep neckline and sleeveless gown. The self-conscious looks and sensuous poses of models indicate how the stereotypical image of a Pakistani bride is being redefined. 


\section{Male Portrayal}

All the ads seem to strengthen the stereotypical roles assigned to men through ages by the media, be it print or electronic media. Men have always been portrayed as physically strong, independent and tough. Similarly all the ads under study reinforce the masculine identity attributed to men in general and in Pakistani context in particular, i.e. confident, bold, selfassured and a productive part of the society. In Pakistan men enjoy the position of hierarchical dominance; as a result, they are usually associated with masculinity, strength, and power.

\section{Gaze}

The men in the ads look confident with an air of assertiveness and poise in their demeanors. This confidence is apparent in their postures, facial expressions, and above all, in their gaze that is mostly directed towards the camera. Unlike the female models in the ads who are found to be mostly looking away from the camera, the male models are often seen with a direct gaze at the camera. Even when the men are not looking at the camera, or are gazing elsewhere, they appear to be self-assured and confident. Consider Fig. 18 and Fig. 19 for instance.

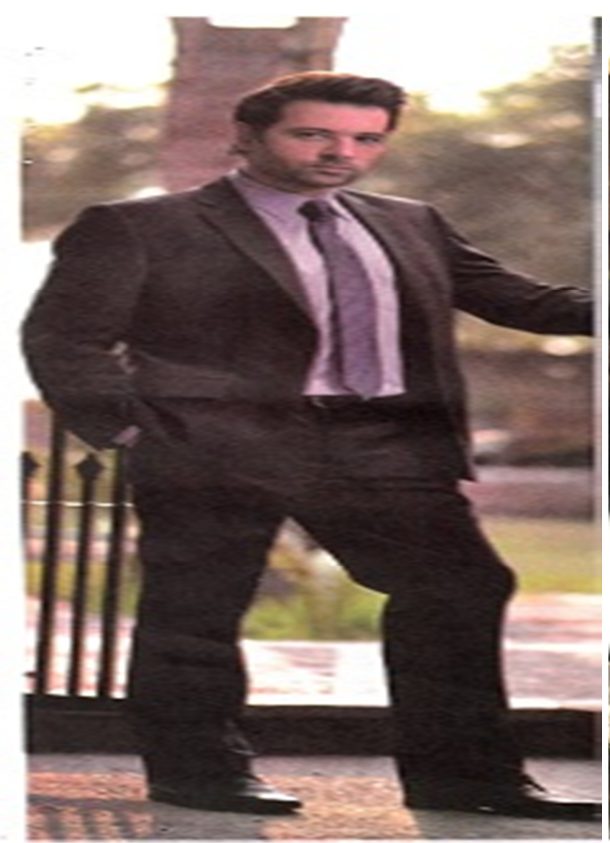

Fig. 18

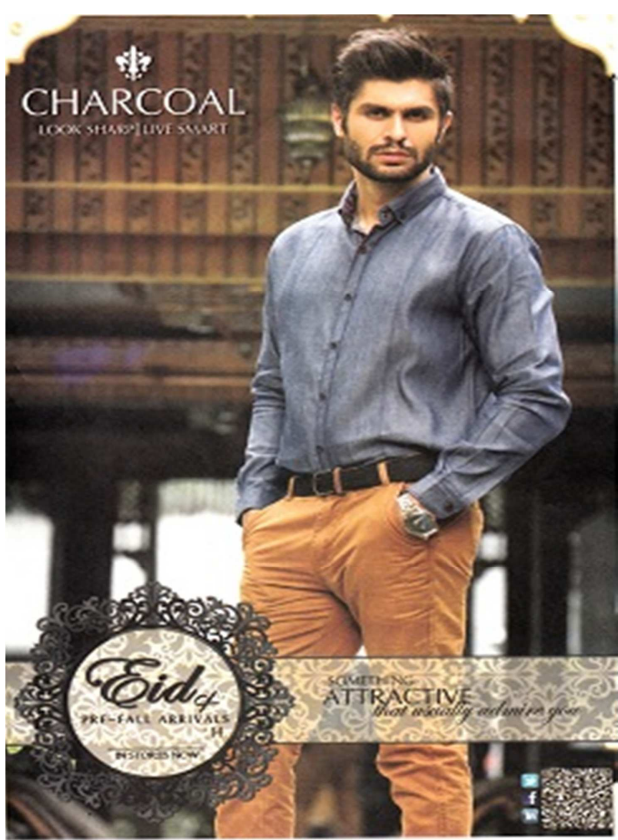

Fig. 19

In both these figures, the male models are directly staring at the camera with an air of confidence and self-assuredness. These images correspond to the stereotypical masculine identity related to confidence and poise, usually associated with men in our society. 


\section{Posture, Style and Attitude}

Just as women are depicted as sensuous, men are depicted to be stiff, inflexible and selfassured with the help of assertive looks and expressions. Refer to Fig.20, in which a model each from both the genders is shown:

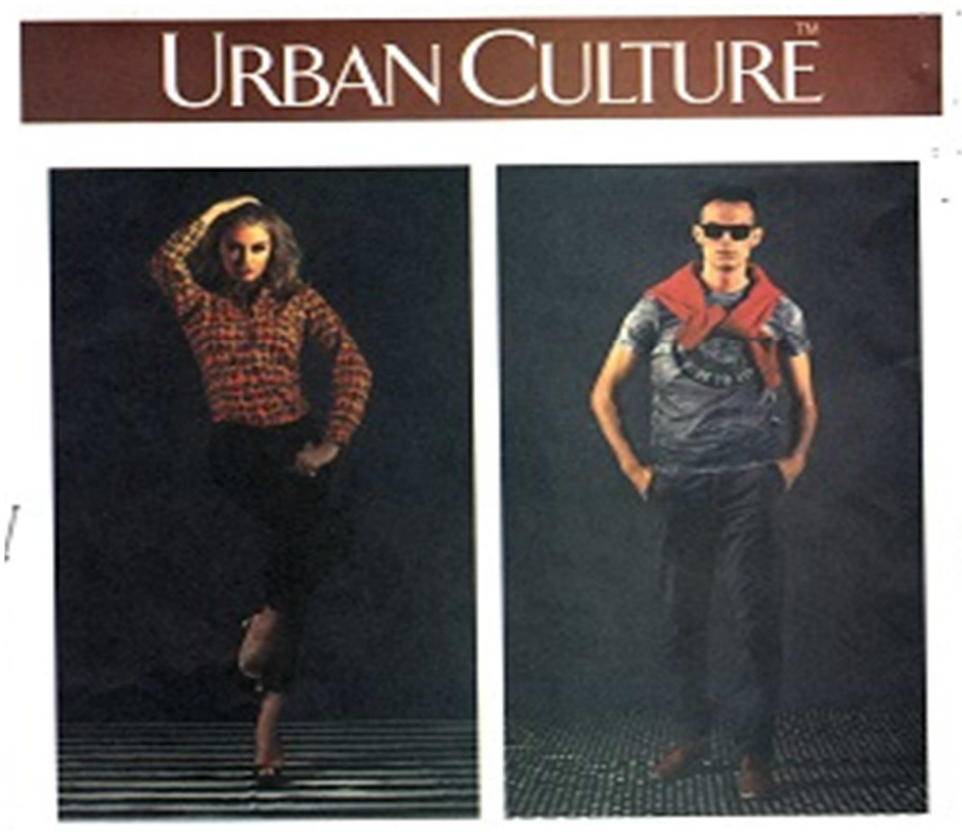

Fig. 20

The ad is by the brand 'Urban Culture' which designs clothing lines that are more inclined towards the west. In this ad the male and female model have been shown in separate parallel blocks and we can immediately notice the gender ideologies that are being created: the facial expressions of the girl and the pose in which she stands give the ad a sensuous overtone; whereas, the man in the ad is shown to be standing straight, wearing sun glasses, facing directly towards the camera.

\section{Age}

In a couple of ads for men's clothing an elderly male model is shown with a dignified image as a symbol of pride and national identity. In an ad of men's clothing by the brand 'GulAhmed' (see Fig. 21) a legendary Pakistani cricketer is the model who serves to associate the brand with national pride. 


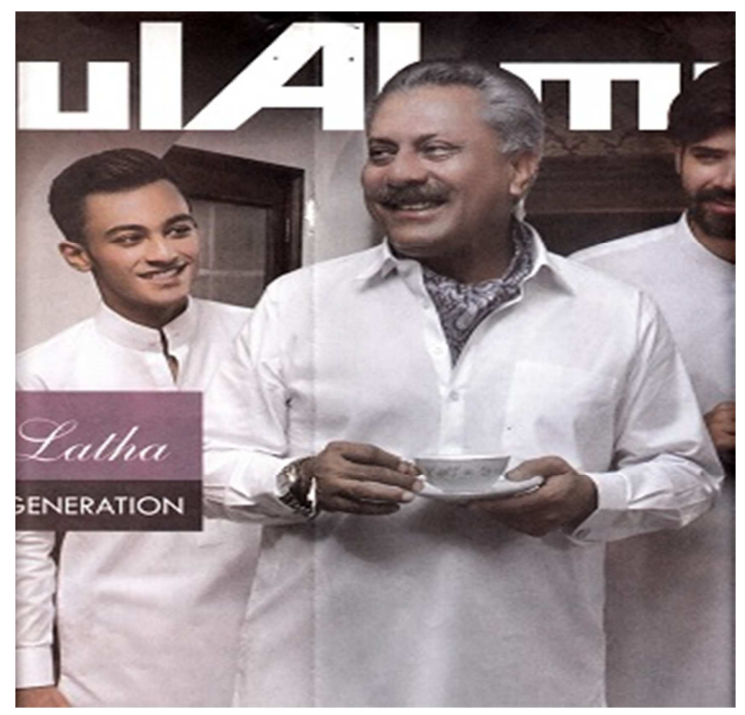

Fig. 21

'GulAhmed' is an old clothing brand in Pakistan with a classical approach that has always claimed for excellence of fabric. The products of the brand cater for both young and middle aged clients. The identity of the brand being a classic is associated with the legendary Pakistani cricketer. Hence, the age here serves as a tool to represent the traditional identity and experience as regards the clothing line being manufactured by the brand.

\section{Roles played/Activities Performed}

The study reveals that men are depicted in more diversified roles, ranging from sportsmen and being involved in outdoor activities, to family men and bridegrooms (see Appendix 2).Consider a few examples from the data for instance.

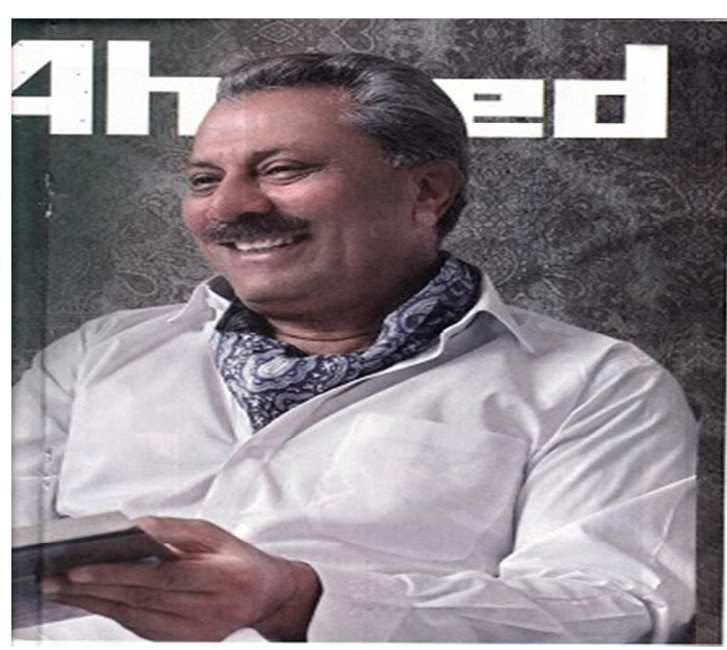

Fig. 22

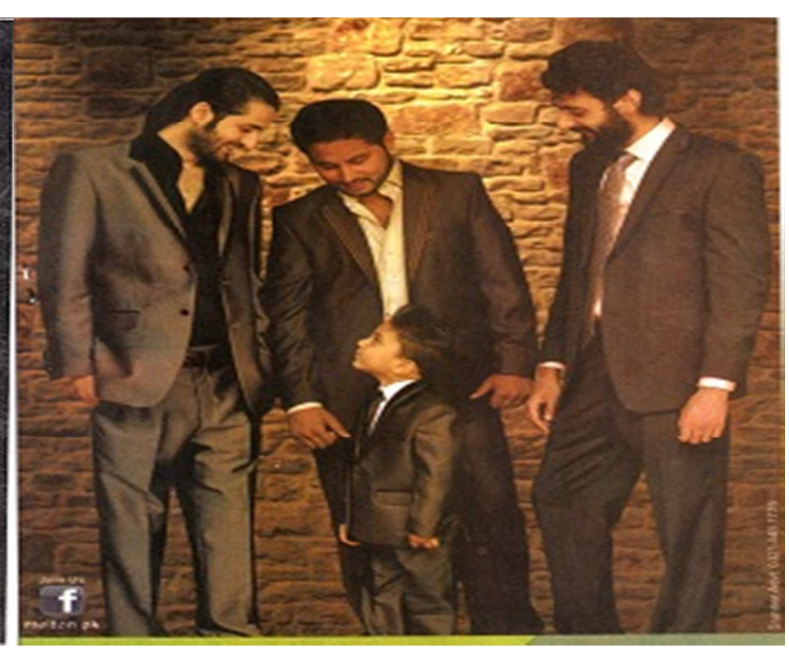

Fig. 23 


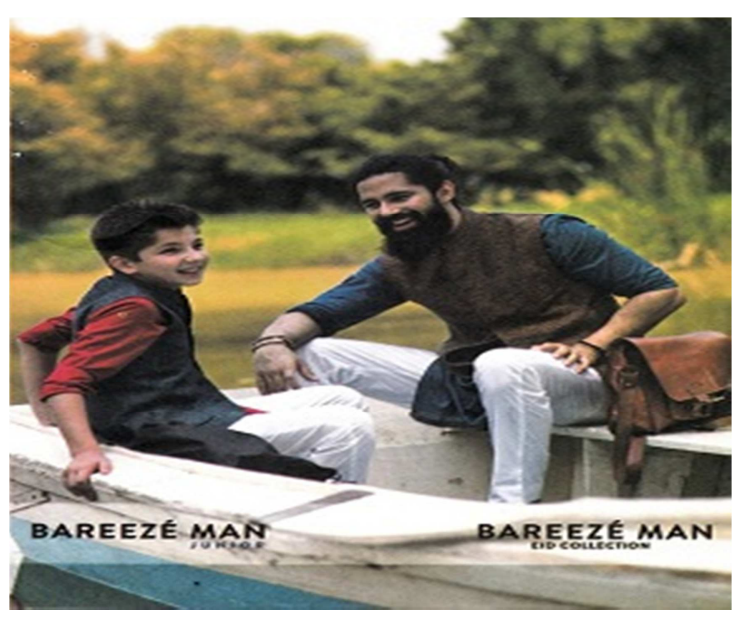

Fig. 24

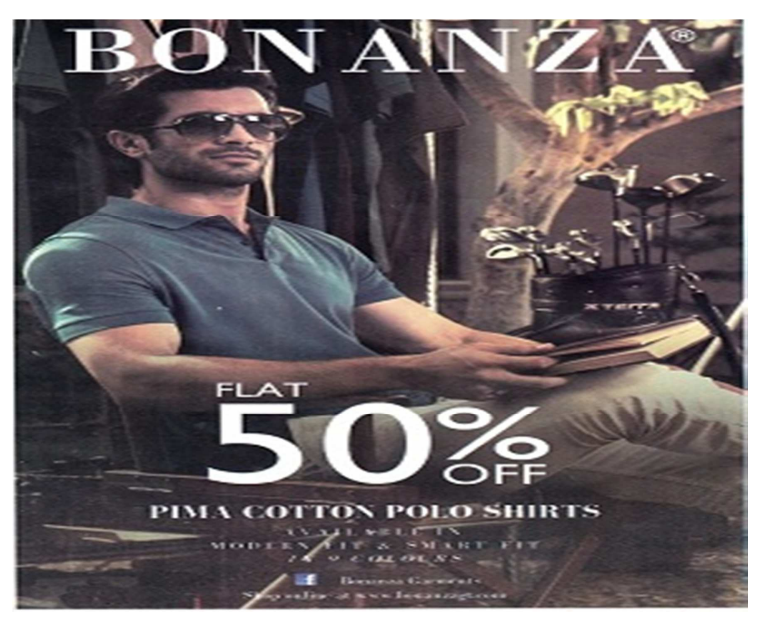

Fig. 25

Here we can see the male models to be involved in certain indoor activities such as reading, boating and spending time with kids etc. Hence, it can be concluded that men are shown in more diversified roles than women in these print ads.

\section{v. Identity}

In the ads featuring both men and women it is observed that both men and women are assigned the stereotypical roles. There is a kind of a legalization of masculine behaviours. Consider Fig. 26 which has a male and a female model.

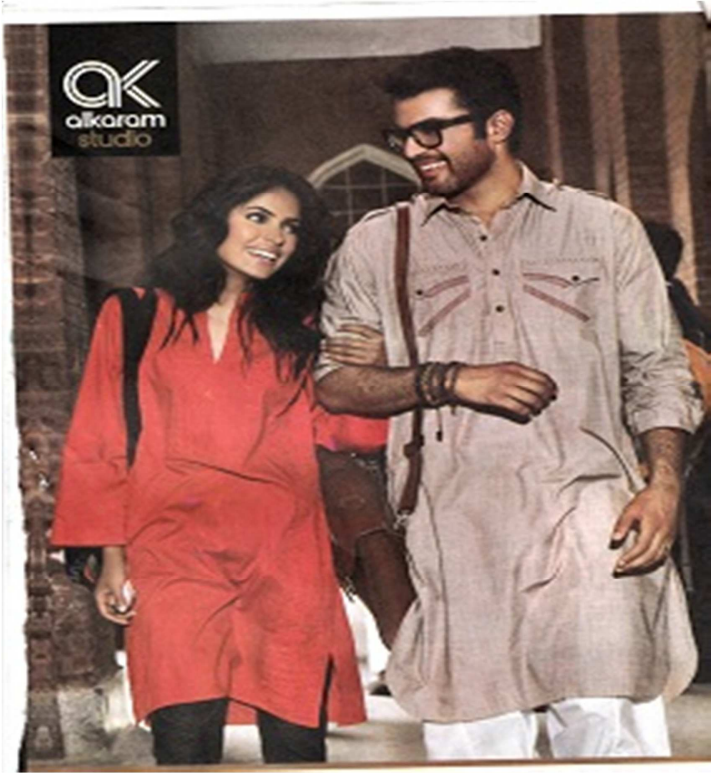

Fig. 26 
Here we can notice the female model leaning over the male models arm/shoulder (apparently physically, but on a symbolic level, emotionally as well). A further closer look establishes that the male is one step ahead of the female.

Here is another male model (see Fig. 27):

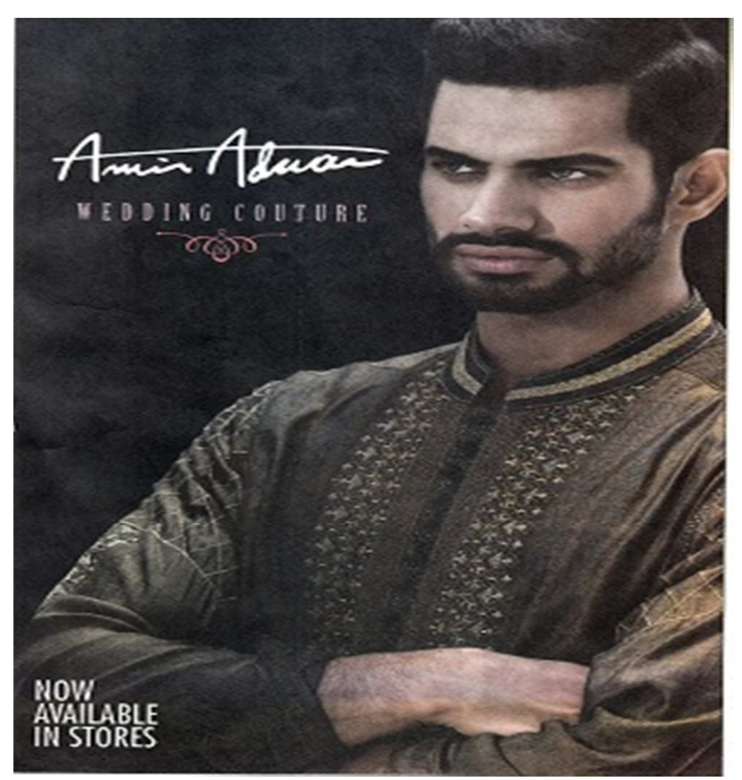

Fig. 27

The model poses with a very aggressive look that somehow shows strength and attributes a more masculine identity to the male model in the ad. Thus giving a more aggressive identity to men in general and also displays their physical strength. The physical strength usually associated with men in our society is also hinted at in various other ads. Idea of masculinity is reinforced through media representations of male body parts like chest, thighs, biceps etc. that refer to the masculinity of the male models. Moreover, in most of the ads of men's suiting mostly only half of the body is shown. This is contrary to what women's portrayal in the ads is where showing the skinny figure of the female model is customary.

A new kind of identity with respect to men is also observed. Traditionally, men did not enjoy the stage when it came to advertisements in general and print ads in particular. But in the current research it is observed that male models are used in quite a big number. In a total of 23 ads designed specifically for men, 38 male models are present. There are 5 ads in which more than one male model are shown.

Moreover, since recently the overall trend of branded clothing has gained popularity in Pakistan, the brands that initially provided products for women, are now introducing clothing 
collections for men as well. Thus, some already exhisiting brands have started separate clothing lines for men by adding the word 'man' to the brand name. Two such examples from the data are: 'Bareeze man' and 'Chinyere man' (see Fig. 30 and Fig. 31 respectively).

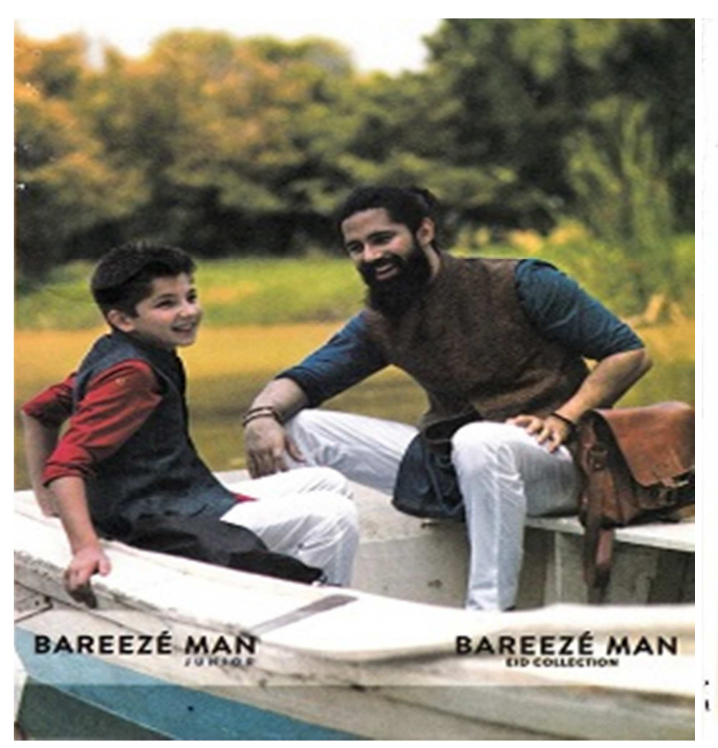

Fig. 30

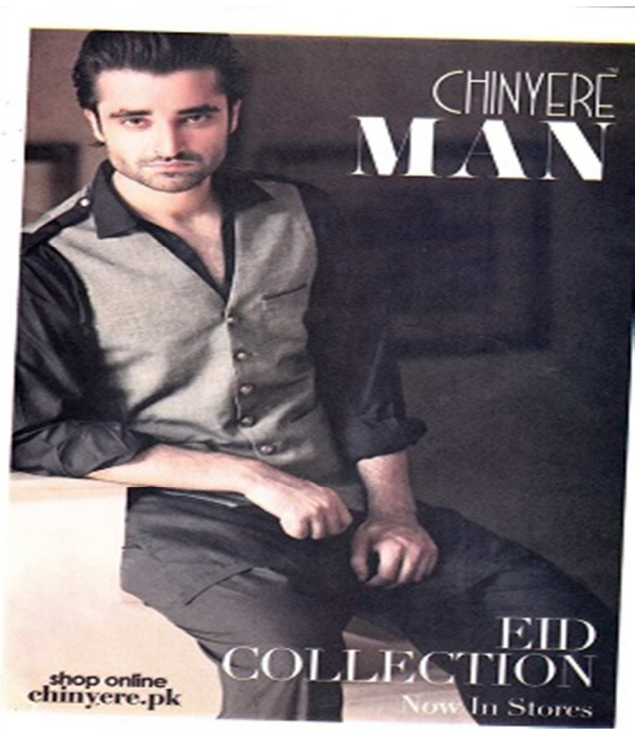

Fig. 31

In Fig. 30, the 'Bareeze man' is a bearded man, projecting the fusion of traditional eastern identity and modern western identity which is represented by blending the eastern and the western wear- a traditional kurta and waist coat together with a pair of pants, accessorized with a trendy bag. He looks cheerful and smiles at a little boy (probably his son) with whom he is riding on a boat. Similarly, the 'Chinyere man' in Fig. 31 also represents the consolidation of the eastern and western male identity by endorsing the Eid collection of the brand in an eastern kurta with tucked up sleeves, and a pair of pants. The direct and confident gaze at the camera and the body posture exhibiting confidence and style with an added sensuousness, reinforces the stereotypical male image.

\section{vi. Bridal Masculine Identity}

A total of 4 advertisements featuring male wedding couture are present in the data. Men in Pakistan are getting more conscious of the way they look on their wedding day or even on other such celebratory occasions. There has been an increasing trend among men to get ready- made dresses for such commemorative gatherings. The increasing trend of advertising the male wedding couture in the Pakistani advertisement context, aspires the young Pakistani men to look like models in the ads and to identify with the image portrayed in the advertisements by the particular brands. The bridegrooms in the ads of men's wedding couture are assigned the same masculine stereotypical dispositions such 
as confidence, self-assurance, composure etc. that are generally associated with them. Consider Fig. 28 and Fig. 29 in this regard.

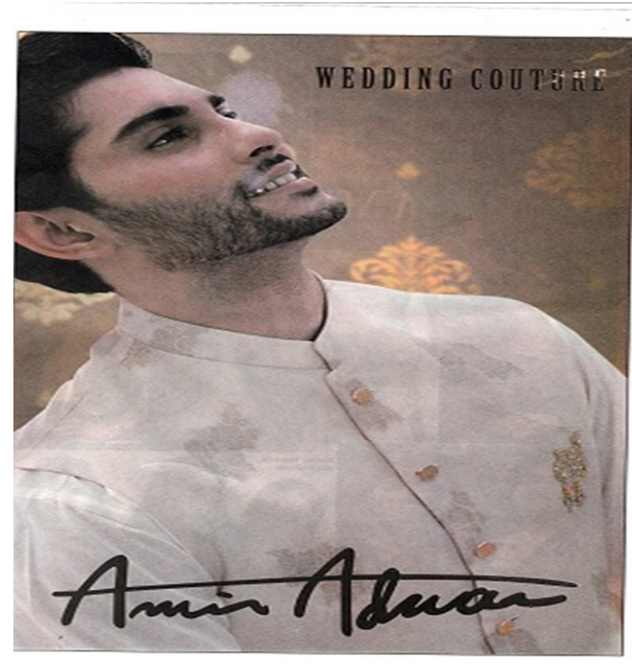

Fig. 28

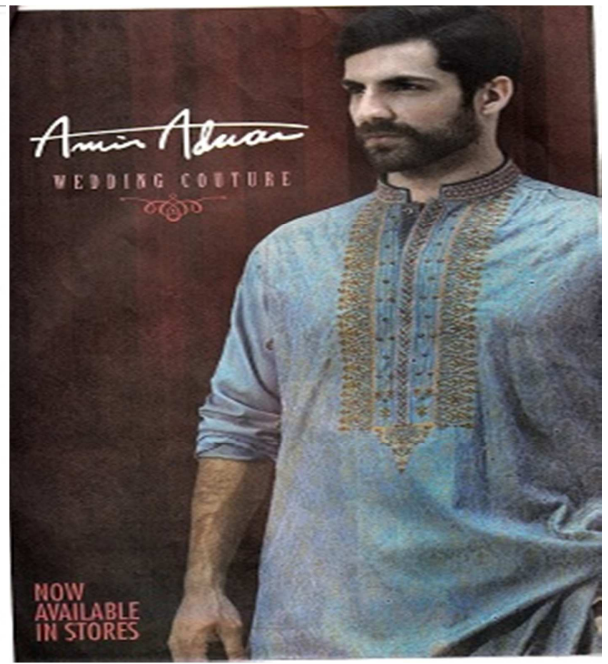

Fig. 29

In Fig. 28 the bridegroom dressed in asherwani (traditional eastern dress for the bridegroom) faces upwards and looks away from the camera with a haughty smile. Similarly, in Fig. 29, the bridegroom stands upright with one hand tucked up on the waist underneath his blue colored kurta, giving a serious but confident look while gazing away from the camera. Hence, the findings indicate the existence and reinforcement of stereotypical gender representations in Pakistani print ads of wedding couture.

\section{Conclusions}

O' Barr (1994) argues that to have an ideological analysis of ads we are required to look at the 'secondary discourses' within the advertisements. The primary discourse concerns with the specific qualities of the advertised product, whereas the secondary discourses are those ideas about social relationships that are embedded within the ads. The contexts and the interaction between the principal actors within the ad are central to these secondary discourses (Croteau \& Hoynes, 1994).The ideology of images in advertisements is found in the ways in which the images in the ads convey messages not only about the qualities of the products being advertised but also about the social contexts in which the ads are produced.

The analysis of gender representation in the ads of clothing brands in the present study shows unequal power relations in Pakistani context. This unequal representation of power of males and females can be studied simply through the body language and poses of males and females in advertising. A male model is portrayed as masculine and dominant usually taking an action shot and rarely posing for the camera. On the contrary, female models are portrayed as very delicate and beautiful, and often objectified in the picture. Men are portrayed as smart and enthusiastic about the passions in their lives whereas the women are hinted at being beauty conscious only. Men are shown to be well dressed and 
serious. In the ads for male wedding couture men are presented as confident whereas women are presented as mere objects of beauty with a hint of sensuousness in their images that depict the brides as sensual objects who are glamorous yet passive products not active members of the society. Where women are seen to be giving either a shy or a sensuous look while gazing away from the camera, men seem to be contemplating something in a solemn mood when they are looking away from the camera.

The findings also indicate that there has been a new trend of advertising of brands, especially of clothing brands in Pakistan. People are now more conscious about their looks and attire. Young men and women of Pakistan aspire to follow the models shown in the ads, owing to the impeccable depictions of style by the male and female models in advertisements. As different clothing brands associate their clothing lines with a certain identity, such as modern, western, eastern, youth, national, masculine or feminine identity etc., the young Pakistanis construct and represent their chosen identity by wearing the clothes associated with the respective identities as advertised by the brands.

\section{End Notes}

1. The word 'ads' has been used interchangeably with the word 'advertisements' in the present study.

\section{References}

Cook, G. (1992). The Discourse of Advertising, London: Routledge.

Craig, R. S. (1992). The Effect of Television Day Part on Sex Portrayals in Television Commercials: A Content Analysis, Sex Roles, vol.26, pp.197-211.

Croteau, D.\&Hoynes, W. (1994). Content: Media Representations of the Social World. UK: SAGE Publications.

Fairclough N. (1992). Discourse and Social Change. Cambridge: Polity Press.

Furnham, A. \& Bitar, N. (1993). The Stereotyped Portrayal of Men and Women in British Television Advertisements, Journal of Sex Roles, vol.29:2, pp.297-310. Department of Psychology, University College London, UK.

Goffman, E. (1979). Gender Advertisement, UK:Macmillian.

Halliday, M.A.K. (1978). Language as Social Semiotic: The Social Interpretation of Language and Meaning, London: Edward Arnold.

Halliday, M. A. K., \&Hasan, R. (1985), Language, Context, and Text: Aspects of Language in a Social-Semiotic Perspective. Geelong, Victoria: Deakin University Press [Republished by Oxford University Press 1989]. 
Jackson, D. (2003). Sonic Branding: An Essential Guide to the Art and Science of Sonic Branding. New York: Macmillan.

Johnson, S. \&Ensslin, A. (eds.) (2007). Language in the Media. London: Continuum International Publishing Group.

Khalid, R. A. (1990). Concepts of Journalism.Karachi: Orient Journalism. Orient Publishing Co. Karachi.

Kilbourne, J. (1999). Beauty and Beast of Advertising, J. Homosex., vol.31:12.

Nixon, S. (1997). Exhibiting Masculinity, In S. Hall (ed.), Representation: Cultural Representations and Signifying Practices. London: Sage Publications

O’ Guinn, T.C., Allen, C.T. \&Semenik, R. J. (2003). Advertising and Integrated Brand Promotion ( $3^{\text {rd }}$ ed.). USA: Thomson.

O’ Halloran, K. L. (in press 2011). Multimodal Discourse Analysis.In K. Hyland and B. Paltridge (eds.) Companion to Discourse. London and New York: Continuum.

O'Shaughnessy, M. \& Stadler, J. (2002). Media and society: An introduction. (2 ${ }^{\text {nd }}$ ed.). Australia: OUP.

Shields, V. R. \&Heinecken, D. (2002).Measuring up: how advertising affects self-image. USA: University of Pennsylvania Press

Signorielli, N. (1989). Images of Women in General Interest and Fashion Magazine Advertisements from 1955 to 2000, London McMillan Publishing Co.

Woods, N. (2006).Describing Discourse: A Practical Guide to Discourse Analysis. London: Hodder Arnold, Retrieved from http://culturalpolitics.net/popular_ culture/textual_analysis

Worell, J. (2002). Encyclopedia of women and gender: sex similarities and differences and the impact of society on gender, vol. 2. USA: Academic Press

Mehreen Umar is Ph.D Scholar in the Department of English, Fatima Jinnah Women University, Rawalpindi.

Dr. Sarwet Rasul is Assistant Professor/ Incharge of the Department of English, Fatima Jinnah Women University, Rawalpindi. 